\title{
Three curved thoracic left-scoliosis after tethered spinal cord surgery
}

\author{
Petra Gröbl ${ }^{*}$, Christa Lehnert-Schroth \\ From 10th International Conference on Conservative Management of Spinal Deformities - SOSORT 2013 \\ Annual Meeting \\ Chicago, IL, USA. 8-11 May 2013
}

\section{Background}

The case study describes a patient with scoliosis after tethered spinal cord-symptomatic was surgically resolved at the age of $2 \frac{1}{2}$ months. At that time, the Cobb angle of the thoracic curve was $32^{\circ}$. At the age of 30 months a three curved thoracic left-scoliosis with a Cobb angle of $80^{\circ}$ with serious shape-shift in frontal and sagittal level appeared. At the age of $4 \frac{1}{2}$ years the patient was fitted with a Rigo-Cheneau corset, which guided the breath into the right side.

\section{Methods}

At the age of 36 months, the Schroth treatment was started. At this time, the primary goal was the correction of the hip that was positioned outwards to the right. This sideward movement, combined with a twist of the pelvis forced the thoracic cage into convexity on the left side and left-backward rotation, producing rib prominence. A hyper-correction according to Schroth was instructed: Side-lying on the right, a thick padding underneath the right hip, flexion with lengthening force to cranial with the right arm. The concave side was wide-positioned, thus diverting the breath in that direction. The right ribs showed two tensed areas. Schroth's turn-angle-breathing was always asked for at the concave places and carried out three-dimensionally in connection with the considered lowering of the diaphragm, eventually repositioning the "weak" ribs into their normal place.

\section{Results}

At the beginning of the treatment, there were two visible tensed rib areas, which required tactile stimulus as well as expanse and breathing. After a few months, the right side became stretched and appeared nearly normal.

\footnotetext{
* Correspondence: petra.groebl@fh-joanneum.at

Degree Program Physiotherapy, FH Joanneum Graz, Austria
}

At $2 \frac{1}{2}$ years: Body limp and weak, $\mathrm{X}$ ray $80^{\circ} \mathrm{Cobb}$. At $5 \frac{1}{2}$ years: Posture upright, pelvis straight, body appears steady, incorrect posture of the head equable, $\mathrm{X}$ ray $45^{\circ}$ Cobb.

\section{Conclusions and discussion}

The Schroth method seems to be significantly effective even in scoliosis with contributing neurogenic factors.

Published: 18 September 2013

\section{References}

1. Lehnert-Schroth C: Dreidimensionale Skoliosebehandlung. AtmungsOrthopadie System Schroth (7.Aufl.). Manchen: Urban \& Fischer; 2007.

2. Rigo $\mathrm{M}$, Reiter $\mathrm{CH}$, Weiss $\mathrm{H}-\mathrm{R}$ : Effect of conservative management on the prevalence of surgery in patients with adolescent idiopathic scoliosis. Pediatric rehabilitation 2003, 6.

3. Lehnert-Schroth C: Physiotherapy for scoliosis patients following spinal fusion surgery. Krankengymnastik 1996, 48:212-221.

\section{doi:10.1186/1748-7161-8-S2-013}

Cite this article as: Gröbl and Lehnert-Schroth: Three curved thoracic left-scoliosis after tethered spinal cord surgery. Scoliosis 2013 8(Suppl 2): 013.

Submit your next manuscript to BioMed Central and take full advantage of:

- Convenient online submission

- Thorough peer review

- No space constraints or color figure charges

- Immediate publication on acceptance

- Inclusion in PubMed, CAS, Scopus and Google Scholar

- Research which is freely available for redistribution
C Biomed Central

(c) 2013 Gröbl and Lehnert-Schroth; licensee BioMed Central Ltd. This is an Open Access article distributed under the terms of the Creative Commons Attribution License (http://creativecommons.org/licenses/by/2.0), which permits unrestricted use, distribution, and reproduction in any medium, provided the original work is properly cited. 